\title{
PARADIGMAS CONTEMPORÂNEOS \\ DE ESTUDO DE LINGUAGEM \\ IMPLICAÇÕES NO ENSINO DE LEITURA E \\ ALFABETIZAÇÃO*
}

Durvali Emilio Fregonezi

UEL

\section{$\underline{\text { I - Introdução }}$}

Uma visão histórica do homem e do mundo nos possibilita verificar que as relações homem/mundo, homem/homem e homem/Deus não é a mesma em todos os tempos. Essas relações são transformadas em virtude da própria dinâmica e evolução do homem, da vida e do mundo. A partir dos elementos que seguem, vamos iniciar nossas reflexões.

1. No começo da década de 70 , em conseqüência de uma guerra nos países árabes, houve dificuldades na aquisição, por países da Europa e da América, de petróleo e derivados para produção de energia. Os países produtores de petróleo impuseram regras mais rígidas para a venda $\mathrm{e}$ exportação. Os países importadores, receando a escassez do petróleo, iniciaram pesquisas para a descoberta de fontes alternativas de energia.

* Este texto é uma sistematização das idéias expostas em palestra no Seminário Estadual para alfabetizadores e professores de língua portuguesa, promovido pela SEED-Pr. em Faxinal do Céu, de 2 a 5 de junho de 1996. Conservamos o título da palestra.

\begin{tabular}{|l|l|l|l|l|}
\hline Signum & Estudos da L inguagem & $\mathbf{1}$ & 1998 & $55-72$ \\
\hline
\end{tabular}


2. No início da década de 80 , a humanidade se viu às voltas com um problema também de muita gravidade. Um vírus, o HIV, quando no organismo de seres humanos, provocava a destruição do sistema de defesa do organismo e tornava o portador uma presa fácil a todo tipo de doenças.

3. Este ano, a humanidade ficou sobressaltada. a revista Veja em sua edição de 5/3/97 chamava a atenção em sua capa: "A Revolução Dolly, já é possível clonar o ser humano." Na reportagem, à página 92 , aparece a explicação da palavra clone: " palavra de origem grega que significa broto. É a cópia idêntica de outro ser vivo produzida artificialmente e assexuadamente." A reportagem referese aos cientistas como "cientistas que brincam de Deus..." Ressaltando a relação homem/Criador, o relato de Dolly é metaforizado do seguinte modo: "Para Dolly nascer foi preciso que um anjo torto, desses que andam de jaleco branco, a arrancasse inteira de dentro de outro animal. Como Eva no Velho Testamento, feita com uma das costelas de Adão, Dolly veio ao mundo como um pedaço de outro ser adulto. Ela não tem pai nem mãe. Ela tem apenas origem, uma origem que não é divina."

Os acontecimentos relatados servem como uma amostragem para refletirmos em seus desdobramentos como alavancadores de verdadeiras revoluções. A partir deles, o mundo, o homem e suas relações já não são as mesmas.

Assim como a visão de determinados segmentos do universo se modifica, a linguagem que caracteriza o homem como ser racional e pensante tem seu foco também modificado. Koch (1989) afirma que, com os enfoques recentes da linguagem, os estudos lingüísticos deram um "salto qualitativo."

\begin{tabular}{|l|l|l|l|l|}
\hline Signum & E studos da L inguagem & $\mathbf{1}$ & 1998 & $55-72$ \\
\hline
\end{tabular}


O professor de língua portuguesa, graduado em um curso cujos estudos de linguagem são realizados ainda sob o enfoque tradicional, não está instrumentalizado para transformar em práticas pedagógicas as recentes descobertas no campo dos estudos contemporâneos da linguagem. O professor pode ser comparado a Alice de Lewis Carroll (apud Aranha e Martins, 1989):

“- Gato Cheshire... quer fazer o favor de me dizer qual é o caminho que eu devo tomar?

- Isso depende muito do lugar para onde você quer ir - disse o Gato

- Não me interessa muito para onde... disse Alice.

- Não tem importância então o caminho que você tomar - disse o Gato

- ... contanto que eu chegue a algum lugar acrescentou Alice, como uma explicação.

- Ah, disso pode ter certeza- disse o Gato - desde que caminhe bastante."

O professor em suas práticas pedagógicas não se interessa muito "para onde quer chegar com seus alunos". Então "não tem importância o caminho que toma", isto é, não tem importância sua visão de linguagem inadequada, não têm importância os materiais instrucionais utilizados e sua relação com a visão de linguagem do professor, não têm importância os encaminhamentos das atividades de leitura e escrita.

Recentemente, tendo em vista os acontecimentos de violência policial ocorridos em Diadema (SP) e na Cidade de Deus (RJ) e divulgados à exaustão pelas redes de TV, a revista Veja em sua edição de 16/4/97 trouxe uma relação

\begin{tabular}{|l|l|l|l|l|}
\hline Signum & Estudos da L inguagem & $\mathbf{1}$ & 1998 & $55-72$ \\
\hline
\end{tabular} 
dos deputados que representam a PM (Polícia Militar) na Câmara Federal. Logo após a lista, aparece uma charge. Na parte visual há dois personagens: um repórter e um deputado. Passa-se então o seguinte diálogo:

“- Deputado, o Senhor é da Bancada da PM?

- Negativo. O elemento que disse isso evadiu-se do local e não pode provar nada."

Em um curso para professores de Língua Portuguesa foi solicitado aos professores que depois da leitura do texto respondessem às seguintes questões:

1. O que o repórter perguntou ao deputado?

2. Qual foi a resposta do deputado? Como sabe?

Havia 60 (sessenta) professores no curso. Dois professores (representando, portanto, 3.33\%) afirmaram que, apesar de o deputado ter negado ("Negativo"), ele é o representante da PM, pois a linguagem policial utilizada na resposta confirma ser ele da bancada da PM. Todos os demais professores, participantes do Curso, em suas respostas afirmaram que o deputado não é representante da PM porque respondeu "Negativo".

Desse fato, podemos afirmar que os professores possuem uma visão de leitura que se embasa na leitura como decodificação. A concepção de leitura: "ler é extrair um significado do texto" é a concepção marcante nesses professores.

\begin{tabular}{|l|l|l|l|l|}
\hline Signum & E studos da L inguagem & $\mathbf{1}$ & 1998 & $55-72$ \\
\hline
\end{tabular}




\section{II - Visão histórica dos estudos da linguagem}

Para uma compreensão da mudança de enfoque dos estudos da linguagem é preciso traçar um quadro com as tendências de cada paradigma. Os dicionários de língua portuguesa registram a unidade lexical paradigma como sinônimo de padrão, modelo. Barker (s.d.) conceitua paradigma como: "conjunto de regras que fazem duas coisas: i- estabelece limites; ii- como ter sucesso resolvendo problemas dentro desses limites."

Historicamente, o primeiro paradigma a dominar os estudos de linguagem é o normativo. Na gramática escolar utilizada hoje em todos os graus de educação predomina o estudo normativo da linguagem. Esse estudo caracterizase por um código de leis, segundo o qual, a língua deve ser correta. Há nesse caso uma forma de língua que é a "correta" e todas as demais formas são "erradas"e portanto desvalorizadas. Aqui aparece já um primeiro problema. Qual é a "língua" (forma de língua) eleita como correta? Por vezes jogam critérios históricos, políticos, geográficos...

Essa visão de estudo de linguagem tem sua origem com os gregos. A mistura da língua original de algumas colônias dominadas pelos gregos com o grego clássico imposto pelos colonizadores fez surgir uma língua "corrompida". A linguagem dos grandes autores - Homero, Aristófanes... - que aparecia nos bens culturais da época era bastante diferente da linguagem falada por esses povos que agora eram gregos. Surgiram então as preocupações normativas com o objetivo de disciplinar e preservar a língua "correta".

Os estudos chamados de "estruturais" (ou descritivos) surgiram com o objetivo de descrever a estrutura e o

\begin{tabular}{|l|l|l|l|l|}
\hline Signum & Estudos da L inguagem & $\mathbf{1}$ & 1998 & $55-72$ \\
\hline
\end{tabular}


funcionamento da linguagem. Estudar linguagem não é mais centrar-se em um conjunto de regras para falar e escrever corretamente, mas explicar como é que as palavras se relacionam (se estruturam) para formar o significado. Um enunciado como "FHC falou aos estudantes do Chile", a unidade lingüística "do Chile", por se relacionar com estudantes possui o seguinte significado: em sua viagem ao Chile, o presidente foi convidado a fazer uma reunião com os estudantes daquele país. Se o presidente falou aos estudantes do Brasil através de uma rede de TV, diretamente do Chile, a unidade lingüística "do Chile"relaciona-se com todo o enunciado . Em resumo, os estudos estruturais se caracterizam por regras que estruturam as unidades componentes em um enunciado.

Uma outra vertente dos estudos de linguagem são os estudos mentalistas. O interesse é descrever como os enunciados são gerados e como se relacionam com os enunciados exteriorizados pelo falante. De acordo com esse enfoque, os enunciados se organizariam em nossa mente sob forma de estruturas(profundas), formalizados em termos de categorias - N V (N)- ou em termos semânticos - Agente-V-Objeto da Ação-Instrumento (Ag$\mathrm{V}$ - (O)-(I) ) Como exemplos de enunciados teríamos "O homem furou a bola com um prego"( o homem- agente; V-furar; o Objeto da ação - a bola; o instrumento - o prego). O estudo lingüístico explicaria como essa estrutura foi gerada e as transformações ocorridas entre a estrutura profunda e a estrutura exteriorizada. A estrutura exteriorizada poderia aparecer com o agente apagado: $\mathrm{O}$ prego furou a bola; poderia aparecer também com o instrumento apagado: a bola furou.

\begin{tabular}{|l|l|l|l|l|}
\hline Signum & E studos da L inguagem & $\mathbf{1}$ & 1998 & $55-72$ \\
\hline
\end{tabular}


O objetivo último desse enfoque de linguagem é explicitar as categorias que estão subjacentes a todas as línguas e a hipótese inicial é que existiriam categorias comuns a todas as línguas do mundo - os universais lingüísticos.

Os três paradigmas de estudo de linguagem descritos, embora se caracterizem especificamente, têm como enfoque a língua estudada como sistema, isto é, para o estudo da língua não são levados em conta os elementos que pertencem ao uso da linguagem, à própria produção da linguagem.

Outros enfoques, outros estudos preocupam-se em analisar a língua, - o sistema lingüístico, - levando-se em conta também seus aspectos de uso. Temos assim, outros paradigmas de estudos lingüísticos.

O primeiro deles é o estudo funcionalista da linguagem. A linguagem é vista como um conjunto de funções. Para o estudo da linguagem teríamos que analisar suas funções. Muitos estudiosos formalizaram o estudo das funções da lianguagem (Bühler, Jakobson, Martinet.).

Um outro modelo de estudo da linguagem é o variacionista. A linguagem é vista como um conjunto de variedades e o estudo se preocupa não mais com o "certo" e o "errado" e sim com o uso "adequado" de determinada variedade em situação de uso.

Os estudos de Peirce, incluindo o Interpretante no signo lingüístico, o dialogismo de Bakhtin, a intersubjetividade lingüística de Benveniste, a análise dos "atos de fala" de Austin, bem como os estudos funcionais de Halliday, deram origem ao enfoque da linguagem que domina os tempos atuais. São os estudos interacionistas de linguagem, também chamados de estudos discursivos, estudos pragmáticos ou

\begin{tabular}{|l|l|l|l|l|}
\hline Signum & Estudos da L inguagem & $\mathbf{1}$ & 1998 & $55-72$ \\
\hline
\end{tabular} 
estudos enunciativos. Conforme esse paradigma, para se estudar a linguagem é necessário analisar o sistema lingüístico (enunciado) e também os elementos que participam da própria produção desse enunciado (os elementos ligados à enunciação).

Com esse paradigma, as atividades pedagógicas do ensino de língua portuguesa em nossas escolas-produção de textos, leitura e análise gramatical , sofrem profundas modificações.

Voltando à leitura da charge referida no início da exposição, levando-se em conta o sistema lingüístico, analisando-se o que aparece no código , o personagem deputado, de fato, responde que não é representante da PM. Os elementos ligados à produção da charge - denúncias de violência da PM em Diadema(SP) e Cidade de Deus (RJ), a própria caracterização do texto-charge (um texto que tem como objetivo criticar, satirizar...), a linguagem utilizada pelo deputado-, no entanto, são partes que consideradas contribuem para que o leitor "construa" a significação do texto: embora o deputado tenha respondido negativamente, ele é representante da PM na Câmara Federal.

\section{III - Os estudos contemporâneos de linguagem e a leitura}

Pelos estudos tradicionais da linguagem, a leitura é vista como "extração de significados do texto". Por essa conceituação, o significado de um texto está no texto. O leitor é um elemento passivo que apenas decodifica o texto, extraindo dele o significado. A partir do momento em que os elementos que fazem parte da produção da linguagem - os elementos ligados à interação, elementos

$$
\begin{array}{|l|l|l|l|l|}
\hline \text { Signum } & \text { Estudos da L inguagem } & \mathbf{1} & 1998 & 55-72 \\
\hline
\end{array}
$$


enunciativos - são considerados parte integrante da linguagem, a conceituação de leitura passa por uma transformação. O leitor é elemento ativo na construção do significado do texto. A leitura se dá na interação entre leitor e texto. As informações que estão no texto representam apenas um "input". O leitor processa as informações do texto fazendo uso de informações que constituem seu conhecimento prévio. Kleiman (1989) explicita o conhecimento prévio, afirmando que fazem parte dele: o conhecimento de mundo, o conhecimento lingüístico e o conhecimento textual.

No texto que apresenta o diálogo entre o repórter e o deputado, as imagens, os elementos lingüísticos fazem parte do sistema (é o "input"). Para construir a significação do texto, o leitor deve lançar mão de seu conhecimento lingüístico, de seu conhecimento de mundo e de seu conhecimento textual. A construção da significação, nesse caso, poderia ser assim descrita:

1. Informações que estão no texto:

a- há no texto dois personagens: um repórter e um deputado;

b- o repórter pergunta ao deputado se ele pertence à bancada da PM;

c- o deputado responde de forma negativa.

2. Informações que estão com o leitor e que são utilizadas para o processamento do texto:

a- houve casos de violência policial em Diadema(SP) e Cidade de Deus(RJ). Esses casos de violência foram captados por um amador $\mathrm{e}$ divulgados em redes de TV;

\begin{tabular}{|l|l|} 
Signum & E studos da L inguagem
\end{tabular}

\begin{tabular}{l|l|l|}
1 & 1998 & $55-72$ \\
\hline
\end{tabular} 
b- o público da TV revoltou-se com a violência policial;

c- a charge é um tipo de texto que se caracteriza pela sátira a uma idéia, uma situação ou uma pessoa;

d- a linguagem utilizada pelo deputado para a resposta é caracterizada pela presença de itens lexicais da linguagem policial: elemento, evadiu-se do local, provar.

Da relação das informações que estão com o leitor, as duas primeiras pertencem ao seu conhecimento de mundo, a terceira, ao seu conhecimento textual e a última, ao seu conhecimento lingüístico.

Por esse exemplo, ficou claro que o leitor é um elemento ativo na construção da significação do texto. Se, porventura, o leitor não possuir "esquemas" de conhecimento referentes ao texto, esse não será processado. Para processar as informações do texto, o leitor deve acionar "estratégias de processamento" do texto de forma adequada. Será que os professores que atuam em nossas escolas, através de suas aulas de leitura possibilitam aos alunos o desenvolvimento dessas estratégias? Será que nossos materiais instrucionais de leitura são preparados e organizados de modo que, executando as atividades de leitura, os alunos estão aprendendo a ler? Será que há um ensino de leitura? De modo geral, os materiais de leitura estão organizados do seguinte modo: o texto inicia uma unidade. Após o texto aparecem questões de compreensão, questões de interpretação, questões devocabulário, questões de aplicação e debate. $\mathrm{O}$ professor que faz uso desse material não se encontra devidamente instrumentalizado em teorias de leitura. Sua

\begin{tabular}{|l|l|l|l|l|}
\hline Signum & Estudos da L inguagem & $\mathbf{1}$ & 1998 & $55-72$ \\
\hline
\end{tabular}


formação foi marcada pelas teorias lingüísticas tradicionais. Há uma crença generalizada sobre o desenvolvimento da leitura: os professores acreditam que, realizando as atividades de leitura propostas no material de leitura (livro didático) os alunos se tornarão leitores. Não há uma sistematização, um desenvolvimento das estratégias de processamento do texto.

Uma outra reflexão que deve ser feita é que a linguagem é vista pelo professor apenas como suporte de uma idéia. Halliday(1976) lingüista inglês, um dos precursores do novo paradigma dos estudos contemporâneos de linguagem, em seu estudo sobre as funções da linguagem (função para esse autor deve ser tomada como sinônimo de enfoque, estudo, ponto de vista), afirma que a linguagem possui três funções (isto é, deve ser estudada de três modos):

a- através da função ideacional, a linguagem é vista como o estudo do conteúdo proposicional, como o estudo das idéias veiculadas pela linguagem;

b- a função interpessoal trata das relações que são estabelecidas através do texto entre o autor, seu texto e o leitor. Portanto, além de estudar as idéias veiculadas pela linguagem, devemos perceber essas relações.

Como exemplo, podemos citar o texto publicado na coluna "Datas"da revista "Isto É" e da revista "Veja" em 07.05.97, sobre a morte do psicanalista Eduardo Mascarenhas.

$\mathrm{Na}$ íntegra, o texto:

\begin{tabular}{|l|l} 
Signum & Estudos da L inguagem
\end{tabular}

\begin{tabular}{|l|l|l|}
\hline 1 & 1998 & $55-72$ \\
\hline
\end{tabular} 
1. Revista "Isto É":

"Morreu o psicanalista e deputado federal Eduardo Mascarenhas. Conhecido na década de 80 por tentar popularizar a psicanálise através de programas de tevê, Mascarenhas entrou para a política em 1990 como suplente de deputado pelo PDT e em 1993 filiou-se ao PSDB. No Rio de Janeiro, de causa não divulgada, aos 54 anos. Na terça-feira 29."

\section{Revista "Veja":}

"Morreu o psicanalista e deputado federal Eduardo Mascarenhas. Com uma clientela de artistas e socialites, sempre acompanhado de belas mulheres, Mascarenhas fez algum sucesso em programas de TV e em jornais, discutindo de forma superficial conceitos freudianos. Iniciou-se na vida pública em 1990, eleito pelo PDT. Três anos mais tarde mudou para o PSDB. Dia 29, aos 54 anos, de câncer no pulmão, no Rio de Janeiro"

Lendo o texto guiado pelas idéias veiculadas, pelo conteúdo proposicional, podemos afirmar que os dois textos são o mesmo. A diferença da leitura, porém, está na relação estabelecida através do texto, entre o produtor do texto, seu texto e o leitor. Enquanto o texto da "Isto É" tenta passar uma imagem neutra de Eduardo Mascarenhas e preocupa-se com a referência do texto, a revista "Veja" posiciona-se diante do político e psicanalista, caracterizando-o como um "bon vivant"- "sempre acompanhado de belas mulheres"- e colocando em dúvida sua própria profissão, afirmando que o psicanalista fez sucesso(algum) - "discutindo de forma superficial conceitos freudianos"...

\begin{tabular}{|l|l|l|l|l|}
\hline Signum & Estudos da Linguagem & $\mathbf{1}$ & 1998 & $55-72$ \\
\hline
\end{tabular}


(chamamos a atenção para o uso do adjetivo "superficial")

c- além de estudar o conteúdo proposicional e analisar as relações estabelecidas pelo texto entre o autor, seu texto e o leitor, afirma Halliday que a linguagem ainda deve ser estudada pela sua função textual. Esse estudo da linguagem referese a uma análise da seleção e agrupamento das unidades lingüísticas tendo em vista a formação de textos coesos e coerentes.

$\underline{\text { IV - Atividades escolares de língua portuguesa/visão atual }}$ de linguagem

Embora os paradigmas contemporâneos desses estudos de linguagem tenham começado a se desenvolver no Brasil por volta dos anos 80 , sua divulgação e incorporação ao ensino está sendo muito lenta. Todas as propostas curriculares dos estados brasileiros se fundamentam nesses estudos. Professores que atuam nas redes públicas de ensino têm sido constantemente convocados a participar de cursos de atualização para discussão dos novos paradigmas orientadores dos estudos da linguagem. A maioria dos materiais instrucionais colocados à disposição de professores de língua portuguesa e de alunos da rede pública escolar - através do programa FAE/MEC -, no entanto, ainda se fundamenta em teorias tradicionais de estudo de linguagem. Como o professor, sobrecarregado por atividades docentes, geralmente ministra 40 horas/ aula semanais e não tem tempo disponível para elaboração, organização de seu material, ele toma o livro didático como um guia. Em conseqüência disso podemos afirmar que as

\begin{tabular}{|l|l|l|l|l|}
\hline Signum & Estudos da L inguagem & $\mathbf{1}$ & 1998 & $55-72$ \\
\hline
\end{tabular}


atividades pedagógicas no ensino de língua portuguesa continuam a ser direcionadas pelas teorias tradicionais de estudo de linguagem.

Gregório (1996) faz uma análise de alguns aspectos que dificultam o acesso do professor às teorias contemporâneas. O estudo desenvolve uma relação de elementos chamados de "elementos difusos" que são verdadeira "camisa de força" e impedem uma atualização do professor.

As atividades com a linguagem desenvolvidas na escola com a finalidade de desenvolver habilidades lingüisticas podem ser agrupadas em três categorias: i- atividades lingüísticas que representam o uso da linguagem em processos reais de comunicação; ii- atividades metalingüísticas que são aquelas que são " um falar sobre a língua" e iii -atividades epilingüísticas que são um trabalho de reflexão sobre a língua.

Enquanto no ensino tradicional de língua portuguesa predominam as atividades metalingüísticas, as propostas curriculares de língua portuguesa priorizam as atividades linguísticas e epilingüísticas. $\mathrm{O}$ ensino metalingüístico desenvolve todo um sistema teórico e uma terminologia técnica e as unidades lingüísticas são categorizadas nesse sistema teórico. Daí foi cristalizado o mito: saber língua portuguesa é saber falar sobre a linguagem (Tome-se por exemplo, as avaliações de Língua Portuguesa nos mais diferentes níveis de ensino, bem como as questões de concursos públicos).

O trabalho com a linguagem em consonância com as teorias contemporâneas de aquisição e desenvolvimento da linguagem centram suas atenções nas atividades de reflexão sobre a linguagem - as denominadas atividades

\begin{tabular}{|l|l|l|l|l|}
\hline Signum & Estudos da L inguagem & $\mathbf{1}$ & 1998 & $55-72$ \\
\hline
\end{tabular}


epilingüisticas. Referindo-se a esse tipo de atividade, a proposta curricular da CENP-(Coordenadoria de Estudos e Normas Pedagógicas do Estado de São Paulo) explicita encaminhamentos:

As situações de construção do texto escrito são, muito freqüentemente, o espaço ideal dessa atividade: tornamos conscientes os propósitos do texto, procuramos antecipar a imagem dos interlocutores a que nos dirigimos, esforçamo-nos por adequar a organização do texto e linguagem aos propósistos e aos interlocutores, comparamos e selecionamos para isso os recursos mais expressivos, as figuras mais relevantes, os argumentos mais convincentes. (6)

Como exemplo desse tipo de atividade transcrevemos o texto abaixo, incluído em um estudo de Zilles (1993):

(Narrativa de menina de 6 anos de Porto Alegre)

"l. era uma vez uma menina que tava na floresta

2. daí quando ela tava andando

3. veio um monte de porquinho prá/prá vim buscá ela

4. disse: aqui é muito perigoso, menininha, você tá sozinha aqui?

5. ela disse: tô, mais...

6. aqui é muito perigoso, tem o lobo mau para pegar

7. daí, quando ela não quis acreditá nos TRÊS porquinhos

8. ela/ela foi passeando

\begin{tabular}{|l|l|l|l|l|}
\hline Signum & Estudos da L inguagem & $\mathbf{1}$ & 1998 & $55-72$ \\
\hline
\end{tabular} 


\section{9. daí ela foi presa pelo lobo mau."}

Um trabalho de reflexão sobre a língua, no texto, seria a retomada de referência na linha 2 . O tópico(uma menina) é retomado por uma unidade lingüística menos marcada "ela". Quando usamos a língua em situações reais de comunicação essa é a ordem de "embalagem". Em primeiro lugar, há a menção com nome definido ou indefinido acompanhado ou não por determinantes e/ou elementos caracterizadores. A segunda vez, a menção se utiliza de pronome e a partir daí pode haver a elipse (apagamento). Por exemplo: " $A$ andorinha fez o ninho no telhado da casa. Ela enfeitou o ninho com penas macias para receber os filhotes. Agora passa muitas horas olhando os seus ovinhos".

Uma outra reflexão, ainda sobre a narrativa é a inversão da ordem no enunciado 3. Normalmente, em um enunciado, há a ordem canônica da língua portuguesa sujeito/verbo. No entanto, nesse enunciado há uma inversão. Qual seria a causa? Teria essa inversão alguma funcionalidade?

Naspolini (1996) propõe categorias de análise, nas quais podemos nos basear para um encaminhamento dessas reflexões epilingüísticas. A autora divide as categorias em dois grandes grupos: categorias de conteúdo e categorias de forma. Para cada grupo há uma outra divisão.

Para o conteúdo: coerência/coesão, conectivos, fio condutor e expressividade. Para a forma são enumerados: unidades significativas, estrutura da frase, pronomes pessoais, ortografia e pontuação.

Com base nessas reflexões epilingüísticas é que são centrados os trabalhos com a produção de textos. Os textos então são

\begin{tabular}{|l|l|l|l|l|}
\hline Signum & Estudos da Linguagem & $\mathbf{1}$ & 1998 & $55-72$ \\
\hline
\end{tabular}


reescritos, reestruturados, possibilitando ao aluno o desenvolvimento dos recursos expressivos que o sistema lingüístico coloca à disposição do falante.

Esse trabalho com a produção de textos, que nos estudos tradicionais focalizava o produto, centra-se agora no processo.

A visão interacionista de linguagem e as abordagens enunciativas, focalizando a língua como enunciação, fazem surgir novas categorias de análise. Categorias essas ligadas aos elementos situacionais da linguagem. Não basta ao professor incluir essas novas categorias em seu sistema de noções para falar sobre a linguagem. É necessário ir além. Trata-se de uma nova postura, de uma nova forma de posicionar-se diante da linguagem. Trata-se de ver a linguagem não mais como um simples objeto de análise mas sim como um instrumento colocado à disposicão do aluno para transformá-lo em um cidadão. Enfim, é a linguagem representando um passaporte para a conquista e exercício da cidadania.

$\underline{\text { Referências bibliográficas }}$

ARANHA, Maria L. de Arruda e MARTINS, Maria H. Firme. Filosofando- Introdução à Filosofia. São Paulo: Moderna, 1989.

BARKER, Joel A. Discovering the Future - A questão dos paradigmas. Vídeo editado no Brasil pela Siamar. São Paulo: s.d.

GREGÓRIO, Regina Maria. O Perfil do Professor e as Condiçôes para Execução de um Projeto de Ensino Interacionista em Lingua Portuguesa. Tese de Doutorado. USP, 1996

\begin{tabular}{|l|l|l|l|l|}
\hline Signum & Estudos da Linguagem & $\mathbf{1}$ & 1998 & $55-72$ \\
\hline
\end{tabular}


HALLIDAY, M.A.K. Estrutura e Função da linguagem. In: LYONS, J. (ORG). Novos Horizontes em Lingüística. São Paulo: Cultrix, 1976.

KLEIMAN, Angela. Texto e Leitor-Aspectos Cognitivos da Leitura. Campinas: Pontes, 1989.

KOCH, Ingedore V. G. Lingüística do Discurso: O Salto Qualitativo. Anais de Seminário do CELLIP. Univ. Est. de Londrina, 1989

NASPOLINI, Ana Tereza. Didática do Português-Leitura e Produção Escrita. São Paulo: FTD, 1996

SÃO PAULO. Coordenadoria Estadual de Normas Pedagógicas. Proposta Curricular para o Ensino de Lingua Portuguesa- lo. grau. CENP, 1986.

ZILLES, Ana Maria. "Competência Discursiva na Fase de Alfabetizacão: Inter-Relação entre Pragmática e Sintaxe." LETRAS DE HOJE, v. 28, no. 2, junho 1993. 